\title{
Sudden, Intense, Unexpected and Negative Emotions are a Reactivation Factor of Herpes Zoster
}

Lago-López Patricia ${ }^{1}$, Parrado-Alonso María José1, Villar-Fernández Beatriz ${ }^{2}$, Calheiros-Cruz Teresa

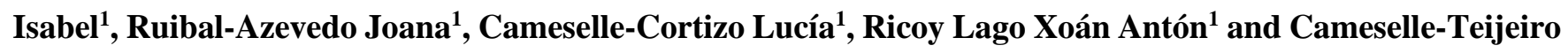
Jorge $\mathbf{F}^{1^{*}}$

${ }^{1}$ Clinical Oncology Research Center ADICAM, Cangas, Spain

${ }^{2}$ Northampton Community College, Pennsylvania, United States

*Corresponding author: Jorge F Cameselle Teijeiro, Clinical Oncology Research Center ADICAM, Travesía de Vigo n² 2, $2^{\circ}$ C VIGO 36206, Spain, Email: videoprimaria@mundo-r.com

Keywords: Herpes zoster; Risk factors; Varicella-zoster virus infection; Stressful life events; Reactivation factors and emotions

Received Date: October 07, 2018; Accepted Date: November 05, 2018; Published Date: November 12, 2018

\section{Hypothesis}

Herpes zoster (figure 1) is caused by a reactivation of residual varicella zoster virus (VZV) which remains latent in the nerve ganglia, after primary chicken pox. Zoster or girdle refers to occurrence of the disease in a segmental distribution. Whereas the majority of cases of chicken pox occur in the younger age group, old age is a major risk factor for herpes zoster. It is usually accompanied by pain, the persistence of which is a problem especially in elderly patients. The disease occurs in a severe form in immunocompromised individuals [1,2].

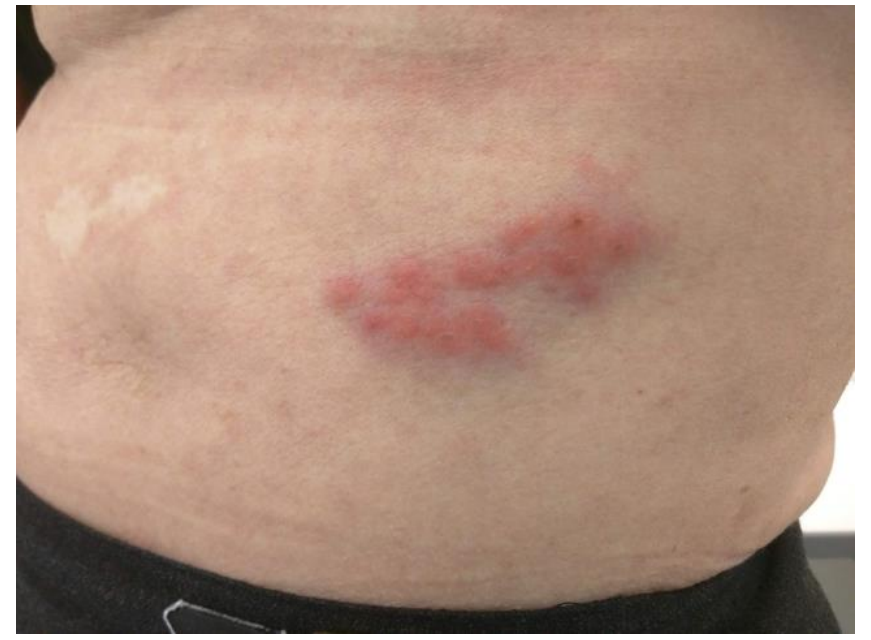

Figure 1: We observed in many immunocompetent people a negative emotional event between fourteen and twenty-one days before the onset of zoster.

Citation: Patricia LL, José PAM, Beatriz VF, et al. Sudden, Intense, Unexpected and Negative Emotions are a Reactivation Factor of Herpes Zoster. J Clin Cases Rep 2(1): 21-24. DOI: https://doi.org/10.46619/joccr.2019.2-1032 
http://www.tridhascholars.org | January-2019

The infection usually presents as two distinct entities: chickenpox (the primary infection) and herpes zoster (also known simply as zoster), a secondary condition. Primary VZV infection typically manifests in children as chickenpox. It is highly contagious but is usually benign, a seasonal viremia that tends to occur in epidemics. Chickenpox is characterized by a generalized rash that begins as maculopapular lesions and progresses to vesicles that spread to the extremities, accompanied by fever [3]. Adults tend to be more seriously ill than children, and they experience more complications.

Infection with varicella zoster virus (VZV) was first documented in the writings of ancient civilizations as a vesicular rash of unknown causes. A relationship between herpes zoster and chickenpox was suggested in 1888 and was finally proven in the 1950s. Since then, much progress has been made in preventing and treating the disease with the introduction of a live attenuated vaccine in 1974, treatment with acyclovir in the 1980s, and complete DNA sequencing in 1986, all of which may ultimately lead to the eradication of VZV infection [4].

Before the use of pediatric vaccines in the U.S., more than $90 \%$ of Americans had chickenpox before the age of 20 [5]. After a VZV infection resolves and immunity develops, latent virus persists in the dorsal root ganglia [6].

Well-recognized risk factors for herpes zoster (HZ), commonly known as shingles, are age and immunosuppression. Numerous studies have investigated other risk factors for $\mathrm{HZ}$ in recent years [7] but we believe that more research is needed to better understand additional risk factors.

The annual incidence of herpes zoster ranges from 1.3 to 4.8 per 1000 population [8]. Any person who has previously had chickenpox is at risk of Zoster. Once we recover from the disease, the virus can integrate into the nervous system and become inactive or "dormant" for many years, but with time it can reactivate, move through the nerves and develop Zoster. However, not every person who has had chickenpox presents Zoster. It is not clearly understood why Zoster develops, but it might be due to a decrease in the immunity against infections that occur as we age. Zoster seems to happen more frequently in aged adults and people with a weak immune system.

The already accepted and well-known factors that increase the risk of zoster include: 1) age (higher risk in older patients), 2) diseases that weaken the immune system such as AIDS or cancer, 3) radiation or chemotherapy, which also weaken the immune system and 4) therapeutic drugs used to decrease the rejection of organs, as well as the prolongued used of steroids such as prednisone. All these risk factors have in common that they affect patients with an already compromised or depressed immune system.

However, in clinical settings, we have less knowledge and awarenes of the "provoking" factors in immunocompetent patients, or individuals with non-compromissed immune systems. Hope-Simpson [9] and Ragozzino et al. [10] believed that HZ is classically associated with physical stress. Brànisteanu et al. [11] found an association between the erythematous form of shingles and young age, while the hemorrhagic or necrotic forms were present in the elderly and/or ill patients. Additionally, in a study of 100 cases, only twelve patients had one or more of the suspected provoking factors. Among them, six were diabetic, four were on steroids, one patient had cancer with chemotherapy and one had an hysterectomy just prior to HZ [12]. In some cases, it has been even suggested the effect of psycologically stressful life events as risks for zoster. Schmader et al. [13] conducted a case-control study of zoster and self-reported recent negative life events and major changes in spousal relationships. These authors found that whereas patients with herpes zoster experienced the same types of life events in the 
http://www.tridhascholars.org | January-2019

year preceding the illness as did the control subjects, recent events perceived as stressful were significantly more common among patients with zoster [2]. These results provide supportive evidence that stressful life events may be risk factors for the reactivation of varicella-zoster virus.

Over our years of clinical experience, we have been able to observe also an association between HZ and sudden emotional events of a negative nature, in immune-depressed patients. These personal events would generally happen two or three weeks before the beginning of symptoms of zoster. We believe that it is very challenging to study or identify the specific cause of this outbreak if it is considered by physicians under the generic term of "stressful life events".

We specifically describe as a "sudden emotional event" any personal experience that happens in an abrupt and non-expected way, affecting the psychological well being of the patient in a very strong negative way. Our experience is showing us that patients considered immuno competent but suffering from HZ, have had a negative emotional event fourteen to twenty-one days before the appearance of zoster. Their negative events consisted of lived experiences that they described to us as very emotionally negative, such as "getting news about a cancer diagnosis, an accident or the death of a loved one", "getting news about the rape of a loved one", "getting news about losing a job", "having to go back to work after a stressful situation "or "being present during a car accident or the killing by accident of someone". These are some of the examples of their descriptions to us, which have always one factor in common: a sudden and intense unexpected, negative emotional response.

We have currently started a prospective study to try to confirm or refute our hypothesis.

\section{References}

1. Sterling JC (2010) Virus infections. In: Burns Tony, Breathnach Stephen, Cox Neil, Griffiths Christopher., editors. Rook's Textbook of Dermatology. $8^{\text {th }}$ (Edn.) Wiley-Blackwell 33: 22-33.

2. Schmader Kenneth E, Oxman Michael N (2012) Varicella and herpes zoster. In: Goldsmith Lowell A., Katz Stephen I., Gilchrest Barbara A., Paller Amy S., Leffell David J., Wolff Klaus., editors. Fitzpatrick's Dermatology in General Medicine. $8^{\text {th }}$ (Edn.) Mc Graw Hill 2383-2401.

3. Cohen JI, Brunell PA, Straus SE, et al. (1999) Recent advances in varicella-zoster virus infection. Annals of Internal Medicine 130(11): 922-932.

4. Wood MJ (2000) History of varicella zoster virus. Herpes: the Journal of the IHMF 7(3): 60-65.

5. Guess HA, Broughton DD, Melton LJ, et al. (1986) Population-based studies of varicella complications. Pediatrics 78(4): 723-727.

6. Gnann JW Jr and Whitley RJ (2002) Herpes Zoster. The New England Journal of Medicine 347: 340-346.

7. Kawai K and Yawn BP (2017) Risk factors for herpes zoster: a systematic review and meta-analysis. In Mayo Clinic Proceedings 92(12): 1806-1821.

8. Chidiac C, Bruxelle J, Daures JP, et al. (2001) Characteristics of patients with herpes zoster on presentation to practitioners in France.(University Claude Bernard, Lyon, France) Clinical Infectious Disease 33: 62-69.

9. Hope-Simpson RE (1965) The nature of herpes zoster: a long-term study and a new hypothesis. Journal of the Royal Society of Medicine 58(1): 9-20

10. Katugampola SL and Katugampola GA (1993) A clinico-epidemiological study of herpes zoster. Journal of Medical Science 36(1): 1-7. 
http://www.tridhascholars.org | January-2019

11. Brànisteanu DE, Stoleriu G, Oanta A, et al. (2014) Clinical-epidemiological trends of herpes zoster: a 5-year study. The Medical-Surgical Journal 118(3): 817-822.

12. Paudel V, Pandey BR, Tripathee R, et al. (2018) Clinical and Epidemiological Profile of Herpes Zoster; A Cross-Sectional Study from Tertiary Hospital. Med Phoenix 3(1): 60-65.

13. Schmader K, Studenski S, MacMillan J, et al. (1990) Are stressful life events risk factors for herpes zoster?. Journal of the American Geriatrics Society 38(11): 1188-1194. 